fácil, particularmente, dada a diversidade geográfica de nosso país, onde há regiões extremamente carentes como as Nordeste e Norte. Assim, como exemplo, a meta 5 , que se refere à redução da mortalidade de crianças menores de cinco anos, visto que há áreas onde esta mortalidade é inferior a 15 por mil, há outras onde é superior a 35 por mil.

Quanto à meta 6, que trata da redução da mortalidade materna, a situação é ainda mais grave. De fato, recente pesquisa realizada na Faculdade de Saúde Pública da Universidade de São Paulo constatou que a taxa de mortalidade materna para 0 conjunto de capitais de Estados do Brasil mais o Distrito Federal é da ordem de 53 por 100.000 nascidos vivos. Há países, os chamados desenvolvidos, onde essa taxa se situa ente 3 a 10 por 100.000 nascidos vivos. Diga-se, a bem da verdade, que o setor saúde, quer em nível federal, quer estadual, tem-se preocupado muito com essa situação e políticas públicas têm sido implantadas. Mesmo assim, será que o Brasil conseguirá cumprir a meta 6 ?

E quanto à meta 2, que trata de reduzir a fome? Muito se tem falado, mas ao que parece, pouco tem sido realizado. Quanto às metas que tratam do ensino, a situação em nosso país, pode-se dizer, é calamitosa; se temos melhorado quantitativamente, do ponto de vista de qualidade de ensino isso deixa muito a desejar.

Em setembro de 2004, a Presidência da República Federativa do Brasil publicou um "Relatório Nacional de Acompanhamento" referente aos "Objetivos de Desenvolvimento do Milênio", cuja apresentação foi feita pelo senhor Presidente da República. Trata-se de um relatório bastante completo, com numerosos dados e informações, referentes à situação no país dos temas incluídos nas metas. Recomenda-se a leitura deste relatório.

Em 1976, a Organização Mundial da Saúde, juntamente com outros organismos internacionais, promoveu uma grande reunião em Alma-Ata, na então União Soviética. Desta reunião surgiu o famoso documento
"Saúde Para Todos no Ano 2000", endossado pela totalidade dos países membros. Também tinha objetivos, metas, propostas, etc. Chegou-se ao ano 2000 e não aconteceu praticamente nada do proposto!

Espera-se que o fato não se repita agora com as Metas de Desenvolvimento do Milênio!

RuY Laurenti

Emergêneia e Medicina Tutensiua

\section{ERROS MÉDICOS ASSOCIADOS COM A DEPRIV AÇÃO DO SONO EM UCI}

Lesões iatrogênicas são comuns em pacientes hospitalizados e são freqüentemente preveníveis. Recentemente, duas pesquisas ${ }^{1,2}$ analisaram a diminuição das horas de trabalho em relaçãa a erros médicos graves em unidade de cuidados intensivos $(\mathrm{UCl})$. Landrigan CP et al., em 2004', realizaram um estudo prospectivo randomizado comparando as taxas de erros médicos graves cometidas por internos enquanto trabaIhavam de acordo com uma escala tradicional (ET) que incluía 24 horas ou mais de trabalho com uma escala de intervenção (EI) com redução do número de horas trabalhadas por semana. De um total de 2.203 pacientes/dia envolvendo 634 admissões, os internos cometeram $35,9 \%$ a mais de erros médicos sérios durante a ET do que durante a escala com um número reduzido de horas. A taxa total de erros graves nas UCls foi 22\% maior durante a ET do que durante a El em relação ao número de horas trabalhadas. Os internos realizaram 20,8\% mais erros graves de medicação durante a ET do que durante a El (99,7 vs 82,5/I000 pacientes/dia, $p=0,03)$. Os internos também cometeram 5,6 vezes mais erros diagnósticos graves durante a ET do que durante a El (18,6 vs 3,3 por 1000 pacientes/dia, $p<0.000$ I). Portanto, diminuindo-se o número de horas trabalhadas pelos internos por semana, pode-se reduzir os erros médicos graves na $\mathrm{UCl}$.

\section{Comentário}

Estas pesquisas analisaram a deprivação do sono e a possibilidade de erros médicos graves, mas é importante que se reconheça também outros fatores latentes, conhecidos como fatores contribuintes que podem causar ou permitir a oportunidade para que ocorra o erro. Os fatores latentes são elementos que interagem e influenciam o funcionamento de uma pessoa ou sistema. Os fatores latentes (presença de fadiga, doença, inexperiência, equipamento inadequado) podem provocar erro ou determinar um ponto de vulnerabilidade (local de trabalho com pobre disponibilidade de equipamentos, pessoal). Quase todos os eventos adversos envolvem uma combinação de um erro ativo dependente da pessoa e de fatores latentes ${ }^{3}$.

Os pacientes pediátricos têm um risco significativamente maior de erros relacionados a drogas, particularmente nas situações de terapêutica com múltiplas drogas, doenças complexas e imaturidade dos sistemas orgânicos. Esta afirmação é particularmente verdadeira em áreas de cuidados intensivos neonatais e pediátricos, locais onde a intensidade das intervenções e cuidados é bastante alta, os pacientes freqüentemente não têm possibilidade de comunicar os sintomas, e os sinais clínicos podem ser difíceis de serem reconhecidos.

Werther Brunow de Carvalho

Referências

I .Landrigan CP, Rothschild JM, Cronin JW, Kaushal R, Burdick E, Katz JT, et al. Effect of reducing interns work hours on serious medical errors in intensive care units. N Eng | Med 2004;35 I ( 8): | 838-48.

2. Lockley SW, Cronin JW, Evans EE, Cade BE, Lee C), Landrigan CP, et al. Effect of reducing interns' weekly work hours on sleep and attentional failures. N Eng J Med 2004;35 | ( | 8): | 829-37.

3. Carvalho WB. Prevenção de erros de medicação: uma visão multiprofissional-médico. In: Harada MJ; Peterlini MA, editores. Erros médicos. São Paulo: Atheneu; 2005. (no prelo). 